\title{
Case-Finding for MS Prevalence Studies in Small Communities Requires a Community-Based Approach
}

\author{
Joel B. Cowen ${ }^{\mathrm{a}}$ Barbara F. Sjostrom ${ }^{\mathrm{a}}$ Andrea S. Doughty ${ }^{\mathrm{a}}$ \\ Randolph B. Schiffer ${ }^{\text {b }}$ \\ a University of Illinois College of Medicine at Rockford, Rockford, III., and ${ }^{\text {b}}$ Texas Tech University \\ Health Sciences Center, Lubbock, Tex., USA
}

\section{Key Words}

Multiple sclerosis, prevalence $\cdot$ Case-finding methods, community-based $\cdot$ Small communities

\begin{abstract}
In response to citizen concerns in 5 small Illinois towns, community-based case-finding determined the prevalence of multiple sclerosis (MS). Potential cases were identified through town meetings, publicity, advocacy groups and local volunteer outreach coordinators. Estimated prevalence based on available medical records for self-identifying individuals for 3 of the 5 communities was high (218-231 per 100,000 population) compared to other studies. Scanning databases in medical offices used in many other studies may miss MS cases; yet tracking medical records is labor-intensive and sometimes restricted by privacy guidelines. MS registries could improve case-finding accuracy and efficiency.
\end{abstract}

Copyright $\odot 2007$ S. Karger AG, Basel

\section{Introduction}

Several methods have been used to identify cases to establish multiple sclerosis (MS) prevalence. Patient selfreports without medical record verification form the basis for the National Health Interview Survey (NHIS), an annual telephone survey involving a US probability sam-

\section{KARGER}

Fax +41613061234 E-Mail karger@karger.ch www.karger.com
(C) 2007 S. Karger AG, Basel

0251-5350/07/0284-0246\$23.50/0

Accessible online at:

www.karger.com/ned ple by the National Center for Health Statistics, which included MS through 1996 [1]. The Agency for Toxic Substances and Disease Registry analyzed NHIS data from 1982 to 1996 to develop regional, age- and sex-specific MS prevalence [2].

In other MS cluster studies, a neurologist has verified MS presence through medical record reviews. A study near a closed Kansas oil refinery reviewed medical records from area neurologists and hospital discharges [3]. In a study for the Illinois Department of Public Health of DePue, Ill., 1 of the 5 communities in this study and the site of a closed zinc smelter, a former resident identified 9 individuals with MS who lived in the area until the age of 18 [4]. Their medical records were then reviewed by a neurologist. The Texas Department of Health sent questionnaires to all persons attending 2 schools near a metal smelter from 1948 to 1970 [5]. A neurologist reviewed the medical records for those who reported having MS.

In a broader effort to establish MS prevalence in Olmsted County, Minn., data for MS have been recorded for a century by the Mayo Clinic and the Rochester Epidemiology Program Project, a shared database of all medical practitioners in the county. All newly diagnosed MS cases from 1985 to 2000 were entered into the database by physicians or hospitals. Records for all identified cases were analyzed with personal or telephone contacts to confirm demographic and disease-related information prior to prevalence determination [6].

Tel. +1 815395 5639, Fax +1 815395 5602, E-Mail joelc@uic.edu 


\section{Methodology}

The current study evaluates the advantages, disadvantages and resulting prevalence found by a community-based approach to the identification and confirmation of MS in 5 small communities of northern and central Illinois where citizens are concerned about disease clusters. Whereas other studies primarily located cases in provider databases such as neurologists' offices, this study relied on resident self-identification. This study may be seen as a test as to whether community case-finding can be an accurate and feasible method for establishing prevalence of a chronic condition.

The community-based case-finding approach is evaluated for the thoroughness of identifying all potentially eligible MS cases in the 5 communities. Secondly, discussion is offered on the feasibility of this methodology compared to others including the effort and resources required to find and confirm cases.

In rural areas of northern Illinois, where the study communities are located, residents travel throughout 3 states for care. No neurologists practice in or near these small places to serve as the locus for analysis. Illinois has not legislated an MS registry.

\section{Study Area}

The study area included zip codes for 5 small communities in northern and central Illinois: Savanna (population: 4,972), an EPA Superfund cleanup site at a closed Army depot with unexploded munitions; DePue (population: 1,677), another EPA Superfund cleanup for a closed zinc smelter plant; Lewistown (population: 4,049), where sludge from the Chicago Metropolitan Sanitary District was spread on agricultural fields; Morrison (population: 7,781), home to an electrical products plant; and Paw Paw (population: 1,298), an agricultural community subject to fertilizer use and pesticide spraying. Two of the communities, DePue and Morrison, had been the subjects of prior MS prevalence studies [4, 7]. Populations are for 2000 Census zip code tabulation areas, a stable Census Bureau zip code approximation during the Census (April 1, 2000) falling approximately at the study period midpoint. These small communities exhibit relatively stable populations with few people migrating in or out.

Four of 5 areas are overwhelmingly white, non-Hispanic, while almost half (47.1\%) of DePue is Hispanic. Savanna, Morrison and Paw Paw are heavily of German ancestry, double the national proportion, while about one fourth of Morrison residents are of Dutch ancestry, compared to the US level of just 1.6\%. All areas except DePue are strongly of northern European descent, thought to be linked to MS. One fifth of DePue residents is foreign-born, primarily from Mexico.

DePue exhibits an excess of males (109.9 per 100 females), while the other communities display gender ratios similar to the US ratio of 96.3. All communities except DePue (median age: 34.5 years) reveal an age structure somewhat older than the nation (35.3). Lewistown is oldest at 41.6. All areas display a higher level of senior citizens than the nation, reaching $21 \%$ in Lewistown.

\section{Inclusion Criteria}

Inclusion criteria were: lived in the study community zip code anytime from 1998 through 2002, had a doctor's visit for MS during the study period and have a diagnosis of MS verified by a neurologist according to $\mathrm{McD}$ onald and Poser international diagnostic criteria. (Though the McDonald criteria are more current, the literature still reports MS prevalence based on Poser criteria for most studies.) Family members could report for deceased individuals meeting eligibility requirements.

Both Poser [8] and McDonald [9] criteria for diagnosing MS primarily rely on evidence of clinical attacks and lesions, though they also consider clinical tests such as cerebrospinal fluid immunological abnormalities and abnormal visual evoked potential tests. McDonald gives greater weight to MRI results, a diagnostic modality not widely used when Poser was developed, as well as provides greater recognition to progressive MS.

\section{Case-Finding Approaches}

Intensive, community-based case-finding was used to identify and enroll residents with a diagnosis of MS. Within each community, a volunteer outreach coordinator, someone with MS or having a family member or friend with MS, was named. Outreach coordinators provided invaluable help by suggesting the best media sources, assisting in organizing town meetings and making personal contacts with potential study participants. Using local citizens as coordinators resulted in outreach campaigns specifically tailored for each community.

Media interest in the project was intense, including front page coverage by the Sunday Chicago Tribune, the Midwest's largest circulation daily. Project staff received hundreds of inquiries as a result of this article, which was carried by the Associated Press, then picked up by newspapers across the country.

During subject recruitment, press releases were sent to all local and regional newspapers, including the weekly 'shoppers' common in small communities, as well as radio and television outlets. Media coverage was widespread with virtually all contacted media publishing articles or running on-air pieces. With broad television and radio coverage across the region, individuals with MS who may have lived in the study communities during the eligibility time period, but had moved nearby or elsewhere in the Midwest, likely received information about the project. News articles posted on the Internet by various newspapers further expanded recruitment efforts.

Local public health departments were informed of the study and disseminated information to potential participants. In DePue, which had been the subject of several investigations as an EPA Superfund cleanup site, the project was presented to the Town Council, which agreed to notify all residents of the MS town meeting in their water bills.

Town meetings were also announced through paid advertisements in the local newspapers and flyers posted throughout each community. In DePue and Savanna, staff from a grassroots community action organization helped schedule the town meetings and distributed flyers. About 20-25 people attended each town meeting.

MS support groups hosted the town meetings at 2 sites. Articles about the study appeared in the statewide newsletters of the National MS Society, Greater Illinois Chapter, which also mailed 40 letters to members residing in the 5 communities describing the study and encouraging eligible individuals to participate.

The Illinois Department of Public Health conducted a search for death certificates listing MS as a cause of death from 1998 to 2002 in the 5 communities. The Illinois Department of Public Health was also contacted for information collected quarterly as part of required Minimum Data Set reports from nursing homes for individuals with an MS diagnosis. In addition, local nursing 
homes in Morrison pledged to help identify potential participants.

Because no neurologists practice in these communities, individuals with MS seek care across Illinois, Iowa and Wisconsin as well as at Mayo Clinic in Rochester, Minn. Due to the broad area, physicians were sent letters about the study only after being identified as a provider by at least 1 person.

\section{Follow-Up and Medical Verification}

Potential participants were sent a 4-page questionnaire regarding their medical history, diagnostic tests, relatives with MS, and residential and occupational history. Also included were 2 forms: 1 to list physicians to contact for the participants' medical records with their consent and the second for consent of the subject to participate in the research. Follow-up by the local outreach coordinator and project coordinator encouraged individuals to return their information. Despite repeated contacts, 5 individuals who initially self-reported did not return the materials and 3 refused to participate.

Medical records were collected from the physicians or hospitals who had treated the individuals or made the diagnoses, often resulting in multiple records for an individual. A trained abstractor summarized the medical findings including the history of symptoms, laboratory reports, MRI reports and other relevant information. A consulting neurologist reviewed the medical abstracts, classifying each person according to both the Poser and $\mathrm{McD}$ onald criteria. Prevalence was then calculated for each community using confirmed cases under each criterion relative to the zip code population.

\section{Results}

Through the intensive case-finding activities, 61 potential MS cases were identified. To learn what case-finding methods were most effective, potential participants were asked for their main referral source. As shown in table 1, the most successful referral sources were the local outreach coordinators, followed by the town meetings. No one cited a local health department or physician as their main referral source.

Forty individuals completed the questionnaires and consent forms. For the 21 individuals who did not, 3 did not live in the area during the study period, and 2 did not see a physician during the study period. An additional 5 did not respond to repeated contacts; 3 surveys were returned as undeliverable; 3 refused to participate; 2 stated they did not have MS; 2 deceased individuals found in the death certificate search could not be identified due to confidentiality restrictions; and 1 deceased individual identified as a potential MS case had no known family contacts for follow-up.

These 21 nonparticipating individuals did not have their medical records reviewed and were not included in
Table 1. Number of study participants by main source of referral

\begin{tabular}{lc}
\hline Referral source & Participants \\
\hline Local outreach coordinator & $24(39.3)$ \\
Town meeting & $17(27.9)$ \\
Family/friends & $9(14.7)$ \\
Press and media & $5(8.2)$ \\
Nursing homes & $2(3.3)$ \\
Death certificate & $2(3.3)$ \\
Advocacy group mailings/newsletters & $2(3.3)$ \\
\hline Total & $61(100.0)$
\end{tabular}

Figures in parentheses are percentages.

the prevalence calculations. Some may have been potentially eligible cases, so the prevalences may be imprecise though some estimate of who is missing is known, while the other provider case-finding methods cannot estimate missing cases. For example, studies which rely on searching neurology databases miss potential cases who do not go to neurologists, some of whom were found in this study.

Those completing questionnaires and the consent forms were asked which physician had the most complete information about their MS, with 33 neurologists, 3 family practice and 3 internal medicine physicians listed by study participants. One person did not list a physician but did name a hospital where she had received an MRI. About 1 in 7 (15\%) listed nonneurologists as knowing the most about their disease.

Participants were also asked for all physicians involved in the diagnosis or care for their MS. A total of 76 medical providers was listed including physicians, hospitals or clinics where tests were conducted and nursing homes. Some participants named as many as 4 different providers holding information about their MS, with a mean of 2.3 providers.

To secure the information necessary for the consulting neurologist to make MS verification, multiple provider contacts and consent forms were required. For some cases, the initial medical record was relatively complete. For others, the participant had to be recontacted to clarify the source with a new consent form completed for additional providers.

Records from as many as 4 providers per case were accessed to obtain the needed diagnostic information for the Poser and McDonald criteria. For 15 participants $(37.5 \%)$ a single medical record was sufficient for com- 
Table 2. Number of records abstracted by provider type

\begin{tabular}{lc}
\hline Provider type & Records \\
\hline Neurologist & $46(60.5)$ \\
Hospital/clinic & $13(17.1)$ \\
Family practice & $9(11.8)$ \\
Nursing home & $6(7.9)$ \\
Internal medicine & $2(2.6)$ \\
\hline Total & $76(100.0)$ \\
\hline
\end{tabular}

Figures in parentheses are percentages.
Table 3. Neurological classification using McDonald and Poser criteria and prevalence rates for the 5 combined communities

\begin{tabular}{lcl}
\hline Criteria & Cases & $\begin{array}{l}\text { Prevalence } \\
\text { per 100,000 }\end{array}$ \\
\hline McDonald & & \\
$\quad$ MS & 30 & 151.7 \\
$\quad$ MS + possible MS & 37 & 187.1 \\
$\quad$ Not MS & 3 & \\
Poser & & \\
$\quad$ Clinically definite/laboratory-supported & \\
MS & 29 & 146.6 \\
MS + probable MS & 33 & 166.9 \\
Not MS & 7 & \\
\hline
\end{tabular}

Table 4. MS prevalence per 100,000 population by gender: study communities combined

\begin{tabular}{|c|c|c|}
\hline Criteria & $\begin{array}{l}\text { Prevalence rate } \\
\text { for males } \\
\text { (population: 9,764) }\end{array}$ & $\begin{array}{l}\text { Prevalence rate } \\
\text { for females } \\
\text { (population: } 10,013 \text { ) }\end{array}$ \\
\hline \multicolumn{3}{|l|}{ McDonald criteria } \\
\hline $\operatorname{MS}(\mathrm{n}=30)$ & 30.7 ( 3 cases $)$ & 269.6 (27 cases) \\
\hline MS + possible MS $(n=37)$ & 30.7 (3 cases) & 339.6 (34 cases) \\
\hline \multicolumn{3}{|c|}{ Poser criteria } \\
\hline \multicolumn{3}{|c|}{ Clinically definite MS/laboratory-supported } \\
\hline MS $(n=29)$ & 30.7 (3 cases) & 259.7 (26 cases) \\
\hline MS + probable MS $(n=33)$ & 30.7 (3 cases) & 299.6 (30 cases) \\
\hline
\end{tabular}

plete information, while $16(40 \%)$ required 2 records to be reviewed, 7 (17.5\%) required 3 records, and 2 (5\%) participants required 4 separate medical record reviews. Table 2 summarizes the 76 medical providers by type contacted to obtain diagnostic information for the 40 participants.

Following receipt and abstracting of medical information, 40 potential MS cases were classified by the consulting neurologist using the Poser and the McDonald criteria (table 3).

The McDonald criteria allowed 4 persons with primary progressive MS to be classified as either definite or possible MS when they were classified as 'not MS' using Poser. For the 5 study communities, the zip code populations totaled 19,777 (2000 Census).

The prevalence estimates per 100,000 are highest in Lewistown (222.3 McDonald and Poser), Morrison (269.9 McDonald and 218.48 Poser) and Paw Paw (231.1 McDonald and Poser). Lower were DePue (59.6 McDonald and Poser) and Savanna (60.3 McDonald and Poser).
Female cases dominated in the study communities as shown in table 4. Depending on whether McDonald or Poser criteria were used, the female:male ratio ranged from 8.7:1 to 11.3:1, far greater than found in earlier studies. For instance, the Olmsted County, Minn., registry in 2000 recorded a female:male ratio of 2.3:1 [6]. Noonan et al. [2] found a ratio of 2.6:1 for the NHIS data 1989-1994 but observed a trend toward a higher proportion of women. The National MS Society states MS is $2-3$ more common among women than men [10]. No reason is known for the female excess in rural northern Illinois MS cases.

\section{Discussion}

The method of case-finding and MS definitions influence MS prevalence. Self-reporting [2] may be too generous by including people who may not meet the diagnostic criteria. Reviewing large databases from hospitals or neurologists [3] may miss people without such contacts. The 
studies of the 2 El Paso, Tex., schools and DePue, Ill., [4, 5] covered an extended prevalence period when the subjects attended school or lived in the community, much longer than the 5-year period in this study. The Olmsted, Minn., criteria exclude those who were diagnosed elsewhere or before 1985 [6].

Advantages are also noted for each approach. Searching physician or hospital databases can identify large numbers of potential MS cases at 1 site without having to contact the patient for consent $[3,6]$. Medical verification of diagnosis using established criteria can be easily obtained from the medical records for identified cases. Studies which included a neurologist's review of the records in DePue and El Paso $[4,5]$ confined their investigation to 1 community. The NHIS [1] and the previous study by this principal investigator in Morrison [7] relied on participant self-identification with no medical record reviews, a much easier methodology for collecting information.

\section{Strengths/Advantages of Community-Based}

Case-Finding Methodology

Due to the multiple approaches used in this study for small communities without a neurologist, case ascertainment is considered thorough due to high community awareness. Extensive local and regional coverage in newspapers, television and radio enhanced participation by reaching eligible individuals living in the study communities during the time period but later having moved. Family members across the country also saw the publicity on the Internet or in newspaper stories and referred relatives.

An important strength of the study was reaching individuals with MS who did not regularly see neurologists as $15.4 \%$ listed family practice or internal medicine physicians as most knowledgeable about their MS. If their conditions are stable or present for many years and the individuals reside in a nursing home, they may be cared for by family practice or internal medicine physicians. Thus, prevalence studies which focus strictly on neurology offices may miss patients not seeing a neurologist during the study period.

Our data suggest that many MS patients see multiple physicians, some at tertiary centers hundreds of miles away. Reviewing all related medical case records is important to obtain complete information.

Involving a local outreach coordinator, someone with a family member or friend with MS, gave additional credibility to the project in the study communities. In addition, cooperation from local government and health de- partment officials enhanced the study's standing and recruitment efforts. Statewide support from advocacy organizations added to the study's visibility and credibility.

\section{Barriers to Case-Finding with Secondary Sources \\ of Data}

Some expected sources were not available or available in a limited manner due to privacy guidelines, discontinuation of data or proprietary control of data by advocacy groups.

The Illinois Department of Public Health searched the death certificates for the 5 communities from 1998 through 2002 for any deaths listing MS as a primary or secondary cause. Due to Health Insurance Portability and Accountability Act (HIPAA) privacy guidelines, information available to the researchers was limited. The request was made to search by birth date in order to allow comparison to the birth dates of identified subjects. The search identified 4 individuals with MS listed as a death cause, 2 of whom were already known and 2 new cases. Since no identification beyond the birth date was known and the medical records could not be reviewed, these 2 cases could not be included in the prevalence calculations. They may or may not represent cases meeting the study criteria.

Two Freedom of Information Act requests were also made to the Illinois Department of Public Health to identify those with a diagnosis of MS living in local nursing homes. Both requests were denied based on HIPAA privacy requirements regarding small numbers and the possible identification of individuals.

The researchers also sought Declaration of Medical Study surveillance authority from the Illinois Department of Public Health to gain access to any Illinois physicians' office to search their records for those with MS living in the 5 communities. The request was denied based upon the opinion that the Declaration should only be used for infectious diseases, not for chronic conditions.

Hospital discharge data for patients with a primary diagnosis of MS were only available publicly through 2001, when the Illinois Health Care Cost Containment Council was disbanded. Since the prevalence data do not list individuals, knowing if those cases had been found through other methods was not possible.

Though the National MS Society Greater Illinois Chapter did not share their mailing lists for use by the researchers, the organization did mail letters regarding the study to individuals in the 5 communities. However, 
these lists may have included donors and other interested parties in addition to those with MS.

\section{Challenges of Collecting Individual Medical Records}

Collecting medical records individually to verify the diagnosis became a time-consuming task complicated by HIPAA privacy requirements, the number of physicians consulted over a wide geographic area and the difficulty of obtaining records from the early diagnostic period for those affected by the disease for many years. Several clinics required a separate consent form beyond the study's IRB-approved form, which then also needed the participants' signature, sometimes causing delays. In a few cases, family members needed to provide Power of Attorney for Health Care papers giving them the authority to act on behalf of a deceased or incapacitated relative.

When received, records from physicians often lacked the information needed to assess the diagnostic criteria for inclusion. Then, records retrieved from other sources such as MRI reports required additional consent forms.

For individuals with MS for 20 or more years, the original diagnostic information was often not available at all, either from physicians or nursing homes, so the criteria could not be met for inclusion. Prior to the 1990s, when MRIs became common, the diagnosis of MS was difficult to make, sometimes being a diagnosis of exclusion. These cases were classified as 'not MS' due to a lack of evidence, though some cases may well have had the disease.

Records were received from 76 providers, making the obtaining of medical records difficult and time-consuming, revealing the challenges of contacting individual providers rather than obtaining records from medical group databases.

\section{Limitations/Disadvantages of the Community-Based Case-Finding Approach}

Since not all potentially eligible MS cases enrolled in the study, prevalence may be underreported. Eight individuals initially contacted refused to participate or did not complete the questionnaire or sign the consent forms. The 2 potential MS cases identified by the death certificate search could not be verified due to HIPAA constraints. Some who lived in the study communities but moved may not be included, though several who had moved but lived in the study communities in the correct time period were identified due to the extensive publicity.

HIPAA requirements proved to be a large obstacle. Obtaining consent forms for such a large set of physicians, clinics, hospitals and nursing homes across 4 states proved to be a challenging task. Several clinics asked for completion of separate consent forms in addition to the IRB-approved form necessitating additional participant contact. Some family members reporting for a deceased or incapacitated relative had to submit their legal Power of Attorney for Health Care papers in order to give permission for the records to be reviewed.

The prevalence of MS in 3 of the 5 communities is elevated compared to approximately 96 per 100,000 (selfreported) for the Midwest region as found by Noonan et al. [2] from the NHIS 1982-1996 and 177 per 100,000 for Olmsted County, Minn., from 1985 to 2000 [6]. MS prevalence has been found to be associated with increasing latitude [11] and northern European ancestry [12] so that comparisons to similar geographic areas, such as the Olmsted County study, are most appropriate.

The possibility exists that because of random statistical variation, many small places could experience elevated MS prevalence. Further, in small places where a high proportion of residents are related, heredity and ancestry may play a strong role in the presence of a disease like MS known to have a genetic association [12]. The distribution of MS among geographic locales is not known. Though the current MS prevalence studies investigated places with suspected elevated MS prevalence and identified environmental risks, most local areas might be able to identify 1 or more environmental risks.

\section{Recommendations/Directions for the Future}

Williamson and Henry [13] emphasized the need for new approaches to MS epidemiological cluster studies. Traditionally, MS cluster studies have compared the number of MS cases in a community to an expected level based on published articles of MS prevalence which vary widely by region and methodology. More accurate estimates of the incidence and prevalence of MS are necessary from a surveillance system such as through registries. The use of a standardized case definition, such as Poser or the newer McDonald criteria, should also be implemented across all studies.

To overcome the lack of agreement in defining cases for prevalence studies, particularly in cluster studies, state mandated registries to provide more accurate data and report chronic diseases like MS should be developed much like cancer, asthma or birth defect registries. In a 2002 report, the US Public Interest Research Group, a nationwide network of nonprofit, nonpartisan, state-based public interest advocacy organizations, recommended developing a national system to more accurately investigate disease clusters which would provide researchers 
with better tools to assess possible environmental links to chronic disease [14].

Admittedly, registries require significant resources, but those potential resources are minimal compared to case-finding. Further, the accuracy would be better, since case-finding is not complete as demonstrated in this study, whereas reporting to registries would be mandated.

\section{References}

1 National Health Interview Survey: Prevalence of selected chronic conditions United States, 1990-1992. Centers for Disease Control and Prevention. Vital Health Stat 1997; 10:39.

-2 Noonan CW, Kathman SJ, White MC: National prevalence estimates for multiple sclerosis based on the National Health Interview Survey. Neurology 2002;58:136-140.

>3 Neuberger JS, Lynch SG, Sutton SB, Feng C, Schmidt WR: Prevalence of multiple sclerosis in a residential area bordering an oil refinery. Neurology 2004;63:1796-1802.

4 Schiffer RB, McDermott MP, Copley C: A multiple sclerosis cluster associated with a small, north-central Illinois community. Arch Environ Health 2001;56:389-395.
5 Henry J, Wagner L: El Paso multiple sclerosis cluster investigation. Texas Department of Health. Dis Prev News 2001;61:1-2.

-6 Mayr WT, Pittock SJ, McClelland RL, Jorgensen NW, Noseworthy JH, Rodriguez M: Incidence and prevalence of multiple sclerosis in Olmsted County, Minnesota, 19852000. Neurology 2003;61:1373-1377.

7 Cowen JB: A study of the prevalence of multiple sclerosis in the Morrison, Illinois, area (unpubl report). Morrison, Whiteside County Health Department.

8 Poser CM, Paty DW, Scheinberg L, et al: New diagnostic criteria for multiple sclerosis: guidelines for research protocols. Ann Neurol 1983;13:227-231.

9 McDonald WI, et al: Recommended diagnostic criteria for multiple sclerosis: Guidelines from the International Panel on the $\mathrm{Di}$ agnosis of Multiple Sclerosis. Ann Neurol April 2001, online version.
10 National MS Society Website. www.nationalmssociety.org, epidemiology topic.

11 Herman MA, Olek MJ, Ascherio A: Geographic variation of MS incidence in two prospective studies of US women. Neurology 1999;33:8.

12 Hogancamp WE, Rodrigues M, Weinshenker BG: The epidemiology of multiple sclerosis. Mayo Clin Proc 1997;72:871-878.

13 Williamson DM, Henry JP: Challenges in addressing community concerns regarding clusters of multiple sclerosis and potential environmental exposures. Neuroepidemiology 2004;23:211-216

14 Dutzik T, Baumann J: Health tracking and disease clusters: the lack of data on chronic disease incidence and its impact on cluster investigations. US Public Interest Research Group US PIRG Education Fund 2002;5-7. 